\title{
Design of a 2-D Cementation Experiment in Porous Medium Using Numerical Simulation
}

\author{
L. Trotignon ${ }^{1}$, A. Didot ${ }^{1}$, O. Bildstein ${ }^{1}$, V. Lagneau ${ }^{2}$ and Y. Margerit ${ }^{1}$ \\ 1 Commissariat à l'énergie atomique, DTN/SMTM/LMTE CE Cadarache, 13108 St-Paul-lez-Durance - France \\ 2 École nationale des mines de Paris, CIG, 35, rue St-Honoré, 77305 Fontainebleau - France \\ e-mail: laurent.trotignon@cea.fr - olivier.bildstein@cea.fr - yves.margeri@@cea.fr - lagneau@cig.ensmp.fr
}

\begin{abstract}
Résumé - Dimensionnement numérique d'une expérience 2D de colmatage en milieu poreux En vue de contribuer à la validation et à la qualification des outils de simulation du transport réactif, une expérience de laboratoire, dans laquelle écoulement, transport par advection/dispersion et transformations physicochimiques affectant le milieu poreux sont fortement couplés, a été conçue et simulée numériquement. Différents montages expérimentaux ont été explorés et testés. La solution retenue met en jeu successivement la précipitation et la perforation d'un obstacle colmatant composé d'oxalate de calcium. Avant qu'une expérience réelle puisse être construite, ce problème est proposé à la communauté scientifique en tant que benchmark numérique. Les simulations qui en sont présentées ici ont été réalisées à l'aide du code couplé chimie-transport Hytec (CIG, École des mines, France).
\end{abstract}

\begin{abstract}
Design of a 2-D Cementation Experiment in Porous Medium Using Numerical Simulation - The validation and qualification of reactive transport simulation tools has motivated the design and simulation, at a laboratory scale, of an experiment in which flow, advective/dispersive transport of solutes and physicochemical transformation affecting a porous medium are strongly coupled. Several possible experimental setups (or designs) have been evaluated using numerical simulation. The selected experimental design involves the successive precipitation and perforation of a clogging obstacle composed of calcium oxalate. Before an experiment can actually be conducted, this problem is proposed as a numerical benchmark for reactive transport codes and simulated using the coupled reactive transport code Hytec (CIG-École des mines, France).
\end{abstract}




\section{INTRODUCTION}

Reactive transport codes are important tools in several areas of applied environmental, earth and engineering sciences. They may be used as predictive or diagnostic tools in different contexts, such as sedimentary diagenesis, reservoir and hydrothermal field exploration (e.g. Le Gallo et al., 1998; Giambalvo et al., 2002), waste disposal (e.g. Trotignon et al., 1998; Savage et al., 2002; Soler, 2003; Bengaouer et al., 2003), soil pollution and radionuclide migration (e.g. Steefel et al., 2003), $\mathrm{CO}_{2}$ sequestration (e.g. Johnson et al., 2001; Lagneau et al., 2004a), etc. With progress both in the knowledge of basic chemical and transport processes and computer capabilities, numerical tools offer increased possibilities in the simulation of reactive transport and are now available for systems of great complexity and extent. One of the problem users are faced with, especially in cases where predictions are made over long time scales or where strong coupling between processes occurs, is to assess the degree of confidence in the results and to be able to evaluate error margins. Several ways exist for building confidence in the use of such tools. The comparison between predictions of system behavior made by different codes using various numerical approaches, is often fruitful. The design of experimental benchmarks dedicated to a specific coupling, although often far from actual field conditions, is another way to validate simulation tools with an external data set. The use of data sets from natural analogues or contaminated sites is a further possibility. In this paper, an investigation is presented with the objective to propose both a numerical benchmark and, eventually, a laboratory experiment that addresses cementation processes in porous medium.
The feedback of chemistry on transport and flow is one of the major coupling effects in a porous medium undergoing chemical and textural evolutions. Several numerical codes are able to handle the coupling of diffusive and advective/ dispersive transport with reaction progress, while evaluating porosity and permeability changes caused by the chemical transformations (Steefel and Lichtner, 1998a, 1998b; Lagneau, 2000; Van der Lee et al., 2003). Few laboratory scale experiments have been conducted to validate the numerical models, with the exception of the 1-D experiments conducted by Lagneau and simulated using Hytec (Lagneau, 2000; Lagneau et al., 2004b).

\section{OBJECTIVE, CONSTITUTIVE EQUATIONS AND NUMERICAL APPROACH OF THE CODE HYTEC}

Our starting point is the work of Lagneau (2000) and Lagneau et al. (2004b) who developed simple column experiments in order to study clogging processes both under diffusion and advection of solutes. These initial experiments were conducted on an inert quartz porous medium in which a reactive phase (calcite $\mathrm{CaCO}_{3}$ or portlandite $\mathrm{Ca}(\mathrm{OH})_{2}$ ) was dispersed. Injection of acid solutions containing dissolved $\mathrm{Zn}^{2+}$ and $\mathrm{SO}_{4}^{2-}$ ions resulted in the isothermal precipitation within the pore space of gypsum $\mathrm{CaSO}_{4} \cdot 2 \mathrm{H}_{2} \mathrm{O}$, smithsonite $\mathrm{ZnCO}_{3}$ or zincite $\mathrm{Zn}(\mathrm{OH})_{2}$ depending on the experimental setting. The net volume change of a transformation such as:

$$
\text { calcite }+\mathrm{Zn}^{2+}+\mathrm{SO}_{4}^{2-}+2 \mathrm{H}_{2} \mathrm{O} \leftrightarrow \text { gypsum }+ \text { smithsonite }
$$

is positive and quite large ( $1 \mathrm{ml}$ of calcite is transformed into $2.9 \mathrm{ml}$ of gypsum + smithsonite, or $1 \mathrm{ml}$ of portlandite into

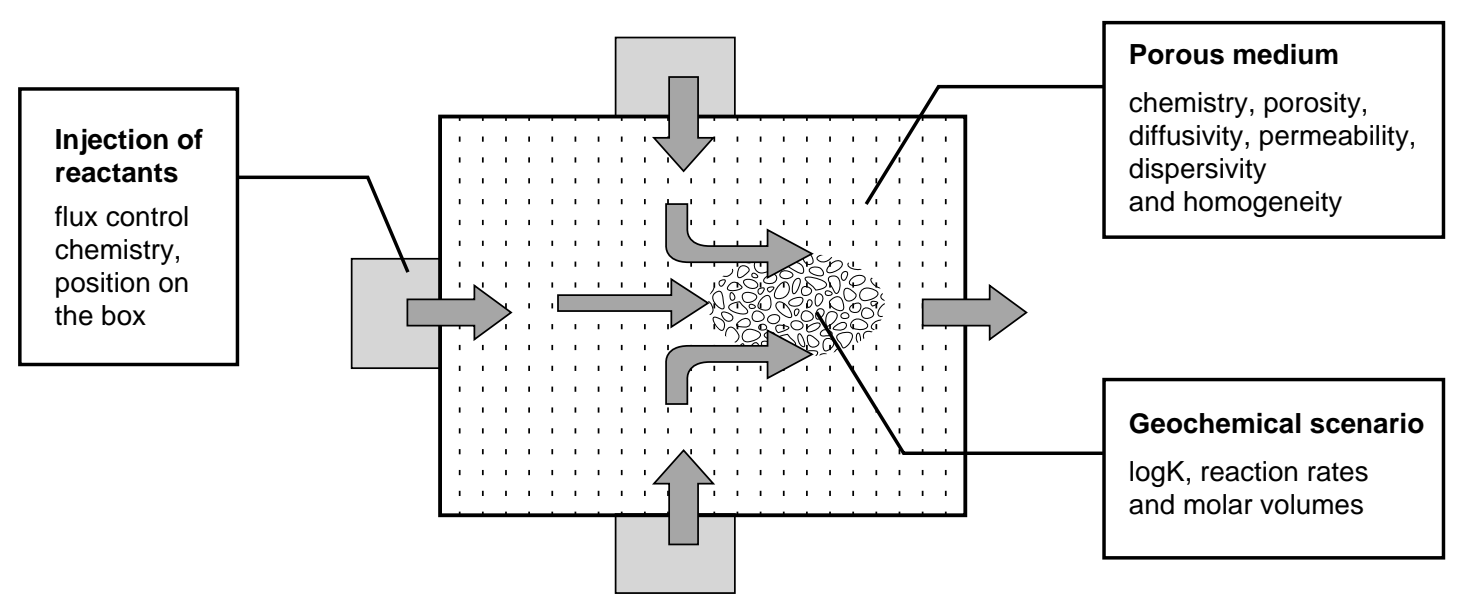

Figure 1

Schematic representation of a 2-D clogging experiment in which different reactants are injected at several inlets in a square reaction chamber. The shaded area in the box corresponds to the zone where strong modifications of the transport properties of the porous medium occur and deviate the flow velocity field, which in turn leads to an evolution of this disturbed zone. 
$2.7 \mathrm{ml}$ of zincite + gypsum, if $\mathrm{Ca}$ is kept constant), leading to a rapid clogging in the vicinity of the reaction front. Moreover, the precipitation of gypsum, smithsonite and zincite is fast and can be assumed to occur at equilibrium. The duration of the clogging experiments performed on a column $($ diameter $=14.6 \mathrm{~mm}$, length $\sim 5 \mathrm{~cm}$ ) was of the order of 10 days in advective mode and up to 6 months for the diffusive set up.

The objective of the present work is to explore the coupling between changes in the local porosity/permeability of the porous medium and changes in the direction and intensity of the flow field. During the 1D experiments, only changes in the pressure drop or magnitude of the fluid velocity could be observed. In order to observe macroscopic changes in the direction of flow lines, a 2-D experimental design is required. The general outline of such an experiment is schematically drawn in Figure 1.

The constraints assigned to the design of such an experiment are:

- it has to be at the bench scale $(\sim 10 \mathrm{~cm}$ characteristic length);

- and the physical duration of the experiment should be, if possible, limited to $\sim 6$ month.

Numerical modelling of the experiment will help to build a scenario (choice of a realistic reaction network) and set plausible experimental parameters (flow rates, dimensions, etc.) to reach this goal.

The governing equations of the problem are obtained in the framework of the physicochemistry of nondeformable porous media. Since all physical quantities relate to a representative elementary volume (REV) of porous medium, the mass balance of species and transport equations are represented by means of partial differential operators using position, time, concentration, porosity, permeability, etc as continuous variables. The different chemical concentration fields are treated using the classical approach of chemical components (Morel, 1983; Yeh and Tripathi, 1991; Steefel and MacQuarrie, 1996; Van der Lee, 1997): all the $m$ species $X_{j}$ with concentration $c_{j}$ in the system can be written using a minimum basis of $n$ components (represented by basis species $\left.C_{i}, i=1, \ldots, n\right)$ with total concentration $c_{i}^{\text {tot }}(i=1, \ldots$, $n<m$ ), using the stoichiometric coefficients $\alpha_{i j}$, so that:

$$
\forall j \in[1, \ldots, m], \quad \sum_{i=1}^{n} \alpha_{i j} C_{i} \leftrightarrow X_{j}
$$

The total concentration of a chemical component $C_{i}\left(c_{i}^{\text {tot }}\right)$ may be considered as the sum of its mobile fraction $\left(c_{i}^{m}\right.$, corresponding to the sum of the concentrations of the soluble species of this component) and of its immobile fraction $\left(c_{i}^{i m}\right.$, corresponding to the sum of the concentrations of the precipitates and other immobile species incorporating the component $C_{i}$ ). The chemical system is thus modelled by a system of algebraic (thermodynamic equilibrium) and/or partial derivative (kinetic control) equations. The transport equation of a chemical component may be written as:

$$
\frac{\partial \omega c_{i}^{m}}{\partial t}=\operatorname{div}\left(D^{*} \operatorname{grad} c_{i}^{m}-c_{i}^{m} \vec{U}\right)-\frac{\partial \omega c_{i}^{i m}}{\partial t}
$$

where $\omega$ is the local porosity, $\vec{U}$ the Darcy velocity and $D^{*}$ the dispersion-diffusion tensor. In this equation, the concentrations are given in mole per volume of solution. In the present case, diffusion and dispersion are isotrope and $D^{*}$ reduces to a scalar form, $D^{*}=D+\alpha|\vec{U}| \cdot D\left(\mathrm{~m}^{2} \mathrm{~s}^{-1}\right)$ is the effective diffusion coefficient assumed to take the same value for all solutes and $\alpha(\mathrm{m})$ is the dispersivity of the porous medium. The local porosity $\omega$ is constrained at any time by the equation:

$$
\omega=1-\sum_{j} \omega \cdot m_{j} \cdot V_{j}
$$

where $m_{j}$ is the concentration (in mole per volume of solution) and $V_{j}$ is the molar volume of the mineral $j$. Note that $c_{i}^{i m}(E q .1)$ is a weighted sum on the concentrations of all immobile species containing the chemical component $C_{i}$, among which are minerals with concentration $m_{j}$ (see Lichtner (1996), for more detail). Two phenomenological laws are assumed to relate porosity, permeability and the diffusion coefficient of solutes in the porous medium:

$$
\begin{gathered}
K=K_{0} \frac{\omega^{3} /(1-\omega)^{2}}{\omega_{0}{ }^{3} /\left(1-\omega_{0}\right)^{2}} \\
D=D_{0}\left(\frac{\omega-\omega_{\min }}{\omega_{0}-\omega_{\text {min }}}\right)^{m}
\end{gathered}
$$

Equation (4) is a normalised form of the Kozeny-Carman relationship (Carman, 1937; Chilingar et al., 1963) adapted by Lagneau (2000) in which $K_{0}\left(\mathrm{~m} \mathrm{~s}^{-1}\right)$ and $\omega_{0}$ are the initial values of the dynamic permeability $K$ and porosity $\omega$. Equation (5) is adapted from the works of Archie (Archie, 1942; Chilingarian et al., 1992). The parameters $\omega_{\min }$ and $m$ are respectively a minimum percolation porosity and the cementation exponent of the first Archie's law. Dependence of dispersivity $\alpha$ on porosity and permeability changes is expected to be small (Sallès et al., 1993a, 1993b), however dispersion (i.e. $\alpha|\vec{U}|)$ should decrease progressively with increasing cementation of the porous medium as the Darcy velocity of the fluid drops. The flow velocity evolution is assumed to be governed by Darcy's law, written here using the hydraulic head $h$ :

$$
\vec{U}=-K \operatorname{grad}(h)
$$

and by the mass balance:

$$
\operatorname{div}(\rho \vec{u})+\frac{\partial(\rho \omega)}{\partial t}=0
$$


where $\vec{u}$ is the fluid pore velocity (related to the Darcy velocity by $\vec{U}=\omega \vec{u}), \rho$ is the fluid density. The dynamic permeability $K\left(\mathrm{~m} \mathrm{~s}^{-1}\right.$, see Eqs. (4) and (6)) is directly related to the intrinsic permeability $k\left(\mathrm{~m}^{2}\right)$ by using the density and dynamic viscosity of the fluid (de Marsily, 1986). In the problem studied here, the density and viscosity of the fluid were assumed to be constant. Under several assumptions (compressibility, etc.), the combination of (6) and (7) leads to the diffusivity equation, i.e.:

$$
\operatorname{div}(K \operatorname{grad}(h))=S_{s} \frac{\partial h}{\partial t}
$$

where $S_{s}\left(\mathrm{~m}^{-1}\right)$ is the storage coefficient (de Marsily, 1986).

In addition chemical equilibrium is assumed both for reactions between solutes and for dissolution/precipitation reactions. Equilibrium constraints are described using the mass action laws linking solute activities, e.g. for an aqueous species $X_{j}$ :

$$
K_{j}^{\mathrm{int}}=\frac{\left[X_{j}\right]}{\prod_{i=1}^{n}\left[C_{i}\right]^{\alpha_{i j}}}
$$

where $\left[X_{j}\right]$ is the activity of the species $X_{j},\left[C_{i}\right]$ is the activity of the basis component species $C_{i}$, $\alpha_{i j}$ is the stoichiometric coefficient of the species $C_{i}$ in species $X_{j}$ and $K_{j}^{i n t}$ is the equilibrium constant for the formation reaction of $X_{j}$ from $C_{i}, i=1, \ldots, n(E q .1)$. Constraints similar to Equation (9) are written for solubility and sorption equilibria. To solve the reactive transport equations, Hytec (Van der Lee et al., 2002, 2003) uses an operator splitting algorithm. The chemical module is the geochemical speciation code Chess (Van der Lee, 1997, 1998) associated with a thermodynamic database giving the equilibrium constants of the reactions involved in the problem. This thermodynamic database is derived from the Lawrence Livermore National Laboratory EQ3/6 DATA0V8R6 database.

The transport module R2D2 solves the diffusiondispersion-advection equation (Eq. (2)) using a finite volume discretization method. Note that although concentrations of immobile components $c_{i m}^{i}$ are taken in mole per volume of solution and become very high when porosity vanishes, this does not seem to hamper the numerical resolution of Equation (2) by Hytec.

At each time step, coupled chemistry/porosity/transport iterations are performed, until a convergence criterion on the total concentrations is reached. Because the chemical speciation computation is performed at each iteration independently on all the nodes, this task can be efficiently parallelized. At each time step, the velocity field is recalculated to take into account the new porosity and permeability fields. When porosity goes done close to $\omega_{\text {min }}$ (see Eq. (5)), mass transfer (particularly reactants) decreases, so that reaction rates simultaneously decrease; it is therefore not necessary to specify cut-off thresholds on precipitation processes. Because of this slow down of reaction progress, minimum porosity is generally not reached but only approached. The algorithm is nevertheless able to stop precipitation reactions in the eventuality of $\omega<\omega_{\min }$, but in practice this is never observed.

Porosity reduction is expected to generate slight overpressure in the system. However, it has been shown that, under usual conditions (normal mineral densities, etc.), the flow rates generated by this overpressure are several order of magnitude lower than typical diffusion rates. Therefore, this phenomenon is not taken into account in Hytec: the pore volume reduction leads to the dismissal of a corresponding volume of pore water. It is clear that the mass imbalance is negligible compared to the mass source term associated with chemistry and transport.

The Hytec code (release 3.2.6) was run on a 12 node computer cluster based on Intel Pentium IV processors $(1.6 \mathrm{GHz})$ operated under Linux RedHat 7.3. Results were post-processed using gpph (the Hytec postprocessor), Matlab and Excel.

\section{EXPLORATION OF VARIOUS EXPERIMENTAL DESIGNS}

In order to define completely the experimental design, a number of features had to be defined:

- the geochemical reaction network or scenario, including what types of precipitates will form; scenarios based on precipitation driven by temperature gradients were not examined in this work;

- the initial state of the porous medium, the location and magnitudes of solute inputs and outputs, the flow rates that will induce the expected evolution of the velocity field;

- the spatial dimensions of the 2-D reaction chamber;

- the type of boundary condition for the solute inputs (imposed flux or imposed hydraulic head).

The geochemical scenarios that were explored were inspired by the previous work performed on columns (Lagneau, 2000). In particular, portlandite and gypsum were considered as potential reactants, with the former serving as a calcium source and the latter as a calcium sink. The possibility to use calcium oxalate as an additional calcium sink was considered because of the low solubility of this mineral phase combined with its large molar volume. Transformations involving the precipitation of ettringite $\left(\mathrm{Ca}_{6} \mathrm{Al}_{2}\left(\mathrm{SO}_{4}\right)_{3}(\mathrm{OH})_{12} 26 \mathrm{H}_{2} \mathrm{O}\right)$ were also examined because of the well known ability of this mineral to clog fractures in alkaline conditions. The three types of geochemical scenarios that were considered may be summarized as follows:

$$
\mathrm{Ca}^{2+}+\mathrm{SO}_{4}^{2-}+\mathrm{C}_{2} \mathrm{O}_{4}^{2-}+n \mathrm{H}_{2} \mathrm{O} \Rightarrow \text { gypsum }+\mathrm{Ca}-\text { oxalate }
$$


$\mathrm{SO}_{4}^{2-}+$ gibbsite + portlandite $+n \mathrm{H}_{2} \mathrm{O} \Rightarrow$ gypsum + ettringite

$$
\begin{aligned}
\mathrm{Ca}^{2+}+\mathrm{SO}_{4}^{2-}+\mathrm{C}_{2} \mathrm{O}_{4}^{2-} & + \text { portlandite }+n \mathrm{H}_{2} \mathrm{O} \\
& \Rightarrow \text { gypsum }+\mathrm{Ca}-\text { oxalate }
\end{aligned}
$$

For all these scenarios, a source of specific ions has to be provided by the input solution. Two main controls are possible for the input of external reactants in the experimental box:

- injection under constant hydraulic head; this procedure ensures that overpressuring cannot damage the porous medium. The drawback is that the clogging will progressively reduce the input rate;

- injection at constant flux (using an imposed flow driven pump); this procedure ensures that constant amounts of reactants are injected in the porous medium. However, a severe clogging could lead to a strong build up of injection pressure, potentially damaging the unconsolidated parts of the porous bed.

Several simulations were conducted using the geochemical scenarios (10) to (12). It appears that, in order to obtain sufficient progress of the clogging and significant changes in the water flow direction, the second option (i.e. injection at imposed flux) should be preferred. In the selected experimental concepts, injection pressures remained low because some dissolution occurred simultaneously with the cementation process.

Two main options were also available with respect to the proposed geochemical scenarios (10) to (12):

- injection of reactants in an inert porous medium, i.e. a porous medium in which chemical components of the clogging mineral are not initially present in the porous matrix;

- preparation of a porous medium containing initially one of the reactants necessary to form the clogging phase. Thus a concentrated and localised source of one reactant is available in the porous medium. The drawback is that the experimental preparation of such a heterogeneous porous medium may be difficult.

Several simulations led to the choice of the second option. It was indeed deduced from simulation results that when reactants are all injected in an inert porous medium (e.g. scenario 10), the newly formed precipitate forms a "wall" between the two reactant influxes, already separated by their respective hydraulic lines (except for dispersion). A hydraulic isolation is transformed into a physical isolation of reactant flows so that the velocity fields are only slightly perturbed after this thin wall has formed.

Finally, the geochemical scenario described by Equation (11), involving the dissolution of aluminium-rich minerals, was discarded because of the complexity of the chemical system and also because potential kinetic limitations were a possible obstacle for the timing of an actual experimental set-up.

For all these reasons, we chose an experimental concept in which reactants (sulfate and/or oxalate ions) are injected at constant flux in a reactive porous medium (containing portlandite); this should lead to the precipitation of gypsum and/or calcium oxalate (Eq. 12). This numerical experiment will now be presented in detail.

\section{DETAILED DESCRIPTION OF THE SELECTED EXPERIMENTAL SET-UP}

\subsection{Geometry and Initial Conditions of the Porous Medium}

The experimental set-up consists of a square reaction chamber (Fig. 2) with two reactant inlets and one fluid outlet. The porous medium is heterogeneous: a rectangular domain is composed of a mixture of quartz sand and portlandite, whereas the rest of the porous medium is composed only of quartz. The exact properties of the porous medium (size, porosity, composition, etc.) are reported in Tables 1 and 2. Because of the rectangular-shape of the portlandite zone which spans the width in the $Y$ direction of the reaction chamber, the actual preparation should not be too complicated.

The initial effective properties of the different zones were evaluated by assuming that the quartz sand was composed of regular spherical grains (diameter $\sim 100 \mu \mathrm{m}$ ) and that the portlandite was composed of very fine grained material (diameter $\sim 1 \mu \mathrm{m}$ ) dispersed in the voids between quartz grains. The values given are however only rough estimations;

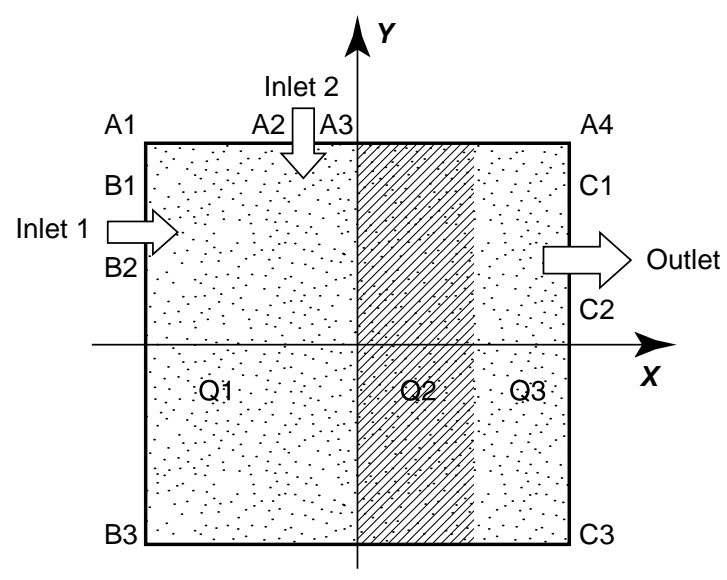

Figure 2

Schematic view of the experimental set up with fluid inlets and outlet and major chemical zones. Letters refer to the parameters detailed in Tables 1 and 2. 
TABLE 1

$X$ and $Y$ coordinates of characteristic points of the experimental set-up displayed on Figure 2.

The origin of $X-Y$ coordinates is taken at the center of the square A1-B3-C3-A4.

The size of the reaction chamber is $280 \times 280 \mathrm{~mm}$

\begin{tabular}{c|c|c|c|c|c|c|c|c|c|c}
\hline & A1 & A2 & A3 & A4 & B1 & B2 & B3 & C1 & C2 & C3 \\
\hline$X(\mathrm{~mm})$ & -140 & -60 & -20 & +140 & -140 & -140 & -140 & +140 & +140 & +140 \\
\hline$Y(\mathrm{~mm})$ & +140 & +140 & +140 & +140 & +100 & +60 & -140 & +100 & +20 & -140 \\
\hline
\end{tabular}

TABLE 2

Properties of the porous medium at the beginning of the experiment

\begin{tabular}{l|c|c|c}
\hline & Q1 & Q2 & Q3 \\
\hline Width $(\mathrm{mm})$ & 140 & 80 & 60 \\
Initial porosity $\omega_{0}$ & 0.30 & 0.15 & 0.30 \\
Initial permeability $\left(\mathrm{m} \mathrm{s}^{-1}\right)$ & $1.010^{-5}$ & $1.010^{-6}$ & $1.010^{-5}$ \\
Dispersivity $\alpha(\mathrm{mm})$ & 20 & 20 & 20 \\
Initial effective & & & \\
Diffusion coefficient $D_{0}\left(\mathrm{~m}^{2} \mathrm{~s}^{-1}\right)$ & $1.010^{-9}$ & $3.010^{-10}$ & $1.010^{-9}$ \\
Storage coefficient $\left(\mathrm{m}^{-1}\right)$ & $10^{-2}$ & $10^{-2}$ & $10^{-2}$ \\
Quartz (mol l-1 of solution) & 102.8 & 205.7 & 102.8 \\
Portlandite (mol l-1 of solution) & 0 & 30.2 & 0 \\
Initial $\mathrm{pH}$ & 6.8 & 12.5 & 6.8 \\
\hline
\end{tabular}

the development of an actual device would imply a precise measurement of these parameters on dedicated column setups.

The minimum value of the porosity (Eq. (5)) was set to 0.02 . The value of $\omega_{\text {min }}$, provided that it is small, is thought not to influence strongly the simulation result but this point deserves further investigations. In practice, this minimum porosity may correspond to a low residual unconnected porosity that is frequently observed in experiments. The Archie power $m$ of Equation (5) for the diffusion coefficient variation law was set to 1.3 , consistently with the previous work of Lagneau (2000) on 1-D sand columns.

\subsection{Input of Reactants and Output Boundary Condition}

The two fluid inlets (Fig. 2) were fed with two solutions containing respectively dissolved calcium chloride (inlet 1 ) and sodium oxalate (inlet 2). Gypsum will therefore not be involved in this scenario: only calcium oxalate will be precipitating. The chemical and physical quantities relative to these fluid injections are reported in Table 3. The injection rates of fluids are such that the initial characteristic time for a nonreactive tracer to cross the box is in the range from 100 to $500 \mathrm{~h}$.

The hydrodynamic boundary condition at inlet 1 and inlet 2 is a constant flux. This is done by specifying the Darcy velocity on the inlet line. For the outlet, a condition of constant hydraulic head is specified $(h=0.0 \mathrm{~m})$.
TABLE 3

Definition of solution chemistry and equivalent boundary Darcy velocity for inlet 1 and inlet 2 . The experiment is led at constant temperature $\left(25^{\circ} \mathrm{C}\right)$

\begin{tabular}{l|c|c}
\hline & Inlet 1 & Inlet 2 \\
\hline $\mathrm{pH}$ & 6.8 & 6.8 \\
$\mathrm{Na}^{+}$(total) $\mathrm{mol} \mathrm{l}^{-1}$ & 0 & 0.8 \\
$\mathrm{Ca}^{2+}$ (total) $\mathrm{mol} \mathrm{l}^{-1}$ & 0.01 & 0 \\
$\mathrm{Cl}^{-}$(total) $\mathrm{mol} \mathrm{l}^{-1}$ & 0.02 & 0 \\
$\mathrm{C}_{2} \mathrm{O}_{4}^{2-}$ (total) $\mathrm{mol} \mathrm{l}^{-1}$ & 0 & 0.4 \\
Darcy velocity vector & & \\
$(U x, U y) \mathrm{m} \mathrm{s}^{-1}$ & $\left(210^{-7}, 0\right)$ & $\left(0,-410^{-7}\right)$ \\
\hline
\end{tabular}

\subsection{Chemical Species and Reactions: Assumptions and Simplifications}

For the purposes of the simulation, the set of chemical attributes given to this reactive system has been simplified. It was first assumed that quartz reacts very slowly as compared to portlandite so quartz was considered as an inert solid. This assumption could possibly be invalid where portlandite is initially present because of the high $\mathrm{pH}$ maintained by this phase. Lagneau (2000), however, has not observed any visible reaction between quartz and portlandite in column experiments with over 6 months reaction time. Next, the chemical species considered in the simulation were reduced to those listed in Table 4.

TABLE 4

List of aqueous and mineral species active in the design simulations

\begin{tabular}{|c|c|}
\hline Basis species & $\mathrm{H}_{2} \mathrm{O}, \mathrm{H}^{+}, \mathrm{Ca}^{2+}, \mathrm{C}_{2} \mathrm{O}_{4}^{2-}, \mathrm{Na}^{+}, \mathrm{Cl}^{-}$ \\
\hline $\begin{array}{l}\text { Aqueous } \\
\text { complexes }\end{array}$ & $\begin{array}{l}\mathrm{OH}^{-}, \mathrm{CaCl}^{+}, \mathrm{CaCl}_{2}(\mathrm{aq}), \mathrm{CaOH}^{+}, \mathrm{NaCl}(\mathrm{aq}) \\
\mathrm{NaOH}(\mathrm{aq}), \mathrm{HCl}(\mathrm{aq}), \mathrm{H}_{2} \mathrm{C}_{2} \mathrm{O}_{4}(\mathrm{aq}) \\
\mathrm{CaC}_{2} \mathrm{O}_{4}(\mathrm{aq}), \mathrm{Ca}\left(\mathrm{C}_{2} \mathrm{O}_{4}\right)_{2}^{2-}, \mathrm{Ca}\left(\mathrm{C}_{2} \mathrm{O}_{4}\right)_{3}^{4-} \\
\mathrm{HC}_{2} \mathrm{O}_{4}^{-}, \mathrm{CaHC}_{2} \mathrm{O}_{4}^{+}, \mathrm{NaC}_{2} \mathrm{O}_{4}^{-}\end{array}$ \\
\hline Minerals & $\begin{array}{l}\text { Portlandite } \mathrm{Ca}(\mathrm{OH})_{2}\left(\text { molar volume }=33.06 \mathrm{ml} \mathrm{mol}^{-1}\right) \\
\text { Calcium oxalate } \mathrm{CaC}_{2} \mathrm{O}_{4} \mathrm{H}_{2} \mathrm{O} \\
\left(\text { molar volume }=66 \mathrm{ml} \mathrm{mol}^{-1}\right)\end{array}$ \\
\hline
\end{tabular}

Finally, the activity of $\mathrm{H}_{2} \mathrm{O}$ was fixed at 1 in all the simulations. The oxalate ion $\mathrm{C}_{2} \mathrm{O}_{4}^{2-}$ was introduced as a new basis species in the thermodynamic database, implying that the 
system is not in redox equilibrium. Several aqueous complexes between the oxalate ion and calcium, sodium and the proton were also introduced using the thermodynamic constants of the Harwell Hatches database (Cross and Ewart, 1991). The equilibrium constant for the Ca-oxalate precipitate was calculated from data given in Lide (1994). Equilibrium constants for the principal reactions are listed in Table 5.

TABLE 5

Equilibrium constants of important reactions involving calcium and oxalate ions. The experiment is simulated at a constant temperature $\left(25^{\circ} \mathrm{C}\right)$

\begin{tabular}{l|c}
\hline Reaction & $\log _{10} \mathrm{~K}\left(25^{\circ} \mathrm{C}\right)$ \\
\hline $\mathrm{CaC}_{2} \mathrm{O}_{4} \mathrm{H}_{2} \mathrm{O} \leftrightarrow \mathrm{Ca}^{2+}+\mathrm{C}_{2} \mathrm{O}_{4}^{2-}+\mathrm{H}_{2} \mathrm{O}$ & -8.631 \\
Portlandite $+2 \mathrm{H}^{+} \leftrightarrow \mathrm{Ca}_{2}{ }^{+}+2 \mathrm{H}_{2} \mathrm{O}$ & 22.55 \\
$\mathrm{H}_{2} \mathrm{C}_{2} \mathrm{O}_{4}(\mathrm{aq}) \leftrightarrow 2 \mathrm{H}^{+}+\mathrm{C}_{2} \mathrm{O}_{4}^{2-}$ & -5.42 \\
$\mathrm{HC}_{2} \mathrm{O}_{4}^{-}-\leftrightarrow \mathrm{H}^{+}+\mathrm{C}_{2} \mathrm{O}_{4}^{2-}$ & -4.19 \\
$\mathrm{CaC}_{2} \mathrm{O}_{4}(\mathrm{aq}) \leftrightarrow \mathrm{Ca}^{2+}+\mathrm{C}_{2} \mathrm{O}_{4}^{2-}$ & -3.00 \\
$\mathrm{CaHC}_{2} \mathrm{O}_{4}+\leftrightarrow \mathrm{Ca}^{2+}+\mathrm{H}^{+}+\mathrm{C}_{2} \mathrm{O}_{4}^{2-}$ & -6.11 \\
$\mathrm{Ca}\left(\mathrm{C}_{2} \mathrm{O}_{4}\right)_{2}^{2-} \leftrightarrow \mathrm{Ca}^{2+}+2 \mathrm{C}_{2} \mathrm{O}_{4}^{2-}$ & -8.1 \\
$\mathrm{Ca}\left(\mathrm{C}_{2} \mathrm{O}_{4}\right)_{3}^{4-} \leftrightarrow \mathrm{Ca}^{2+}+3 \mathrm{C}_{2} \mathrm{O}_{4}^{2-}$ & -8.2 \\
$\mathrm{NaC}_{2} \mathrm{O}_{4}^{-} \leftrightarrow \mathrm{Na}^{+}+\mathrm{C}_{2} \mathrm{O}_{4}^{2-}$ & -1 \\
\hline
\end{tabular}

\section{RESULTS OF THE SIMULATIONS USING HYTEC}

\subsection{Time and Space Discretization, Numerical Settings}

Several calculations were performed with different spatial discretizations. A coarse square mesh of $14 \times 14$ cells was used most of the time to represent the reaction chamber (each cell is $20 \times 20 \mathrm{~mm}^{2}$ ). For some simulations a refined mesh of $42 \times 42$ regular cells was also used (each cell is $6.7 \times 6.7 \mathrm{~mm}^{2}$ ). The time step is constrained by the value of the Courant number for a finite volume cell, which must remain less than or -close to 1 . It was further modulated in order to keep constant the number of iterations before convergence between transport and chemistry. The relative convergence criterion for the coupling was set to $10^{-5}$ and the number of iterations threshold to 10 .

Depending on the selected mesh, the time step remained small and varied between $\sim 10$ and $\sim 200 \mathrm{~s}$. The total physical duration simulated was $4000 \mathrm{~h}$ with the coarse mesh and $5000 \mathrm{~h}$ with the refined mesh. Computation time was about $100 \mathrm{~h}$ with the coarse mesh and $700 \mathrm{~h}$ with the refined mesh when the run was launched on 5 nodes of the cluster machine.

\subsection{Evolution of Precipitates and Porosity}

The coupled evolutions of portlandite, Ca-oxalate and porosity during 5 months are displayed in Figure 3.
Portlandite is progressively replaced by Ca-oxalate from the top of the reaction chamber, and builds an obstacle that progressively grows towards the lower part of the porous medium. When the portlandite is locally completely dissolved, no calcium source can buffer the oxalate-rich fresh solution, and the secondary Ca-oxalate starts dissolving. Portlandite is totally exhausted in about 3.5 months. A localised perforation is predicted to occur at the upper end of the oxalate wall at about 5 months.

\subsection{Evolution of Porosity, Permeability and Flow Field}

The numerical simulations suggest that both the direction and magnitude of the flow velocity evolve as a result of the precipitation and dissolution reactions (Fig. 4). The fluid is focused around the growing Ca-oxalate wall (1 month) until this wall extends across the whole $Y$ dimension of the reaction chamber. At this point, when a first layer of $\mathrm{Ca}$-oxalate wall is formed ( 2 month), a homogenisation of the $U_{x}$ velocity component occurs and a new cycle of wall thickening starts. Another important oscillation occurs (3 months) until the portlandite is totally exhausted (3.5 months). A final major variation of flow field occurs after the wall is perforated (5 month).

It should be noted that the spatial discretization has some effect on the prediction of the exact succession of velocity field oscillations. Indeed, the assumption of chemical equilibrium for dissolution and precipitation processes leads to the fact that the precipitate grows step by step, i.e. essentially cell by cell. A more realistic description of flow field fluctuations would require a comparison of different characteristic times (dissolution, precipitation, diffusion, advection). We would then need to choose the discretization grid so that space and time scales reach a global physical concordance with respect to adimensional scale ratios (Courant, Damköhler, Peclet, etc.).

\subsection{Evolution of $\mathrm{pH}$ and Solute Concentration Fields}

The evolution of the total dissolved calcium, total dissolved oxalate and $\mathrm{pH}$ is reported in Figure 5. It appears that the mean $\mathrm{pH}$ in the experimental box will be high $(\sim 12)$ as long as portlandite is dissolving. This is partly due to the fact that the oxalate solution is poorly buffered with respect to $\mathrm{pH}$ above $\mathrm{pH} \sim 6$ ( $\mathrm{pK} \sim 4.19$ for the protonation, see Table 5). This could also be due to the setting of a large dispersion length, since convective and diffusion/dispersive transport are of the same order of magnitude. The two successive stages of the experiment (wall building and wall perforation) are clearly identified on the evolution of the spatial distributions of dissolved $\mathrm{Ca}$ and oxalate. 


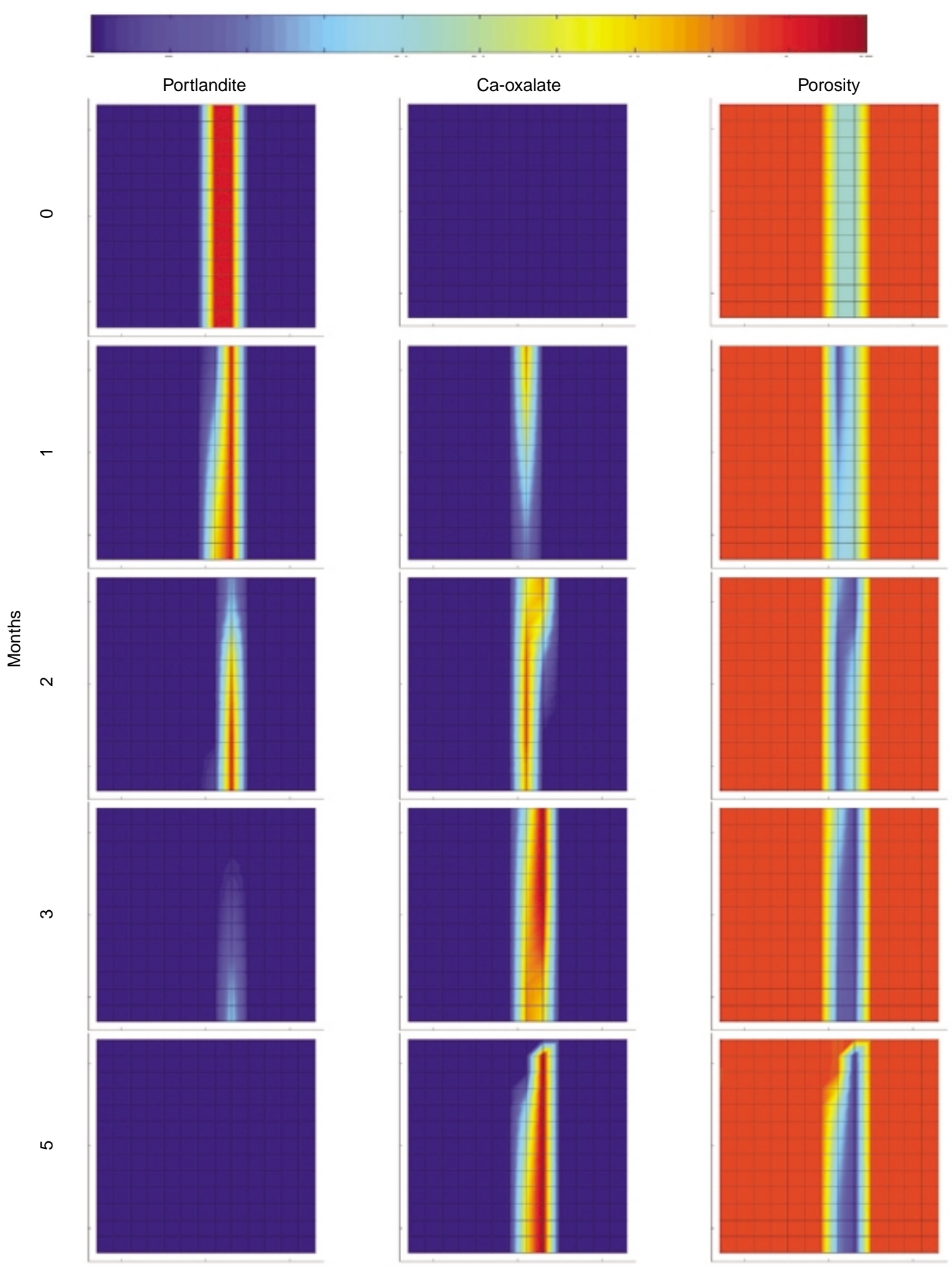

Figure 3

Evolution with time (between 0 and 5 months) of the concentrations of portlandite and Ca-oxalate (mol/l of porous medium i.e. $\omega m_{j}$ ) and of the porosity field. The common colour scale (from blue to red) ranges from 0 to $5 \mathrm{~mol} / \mathrm{l}$ for mineral concentrations and from 0 to 0.35 for porosity (smoothed contours). 


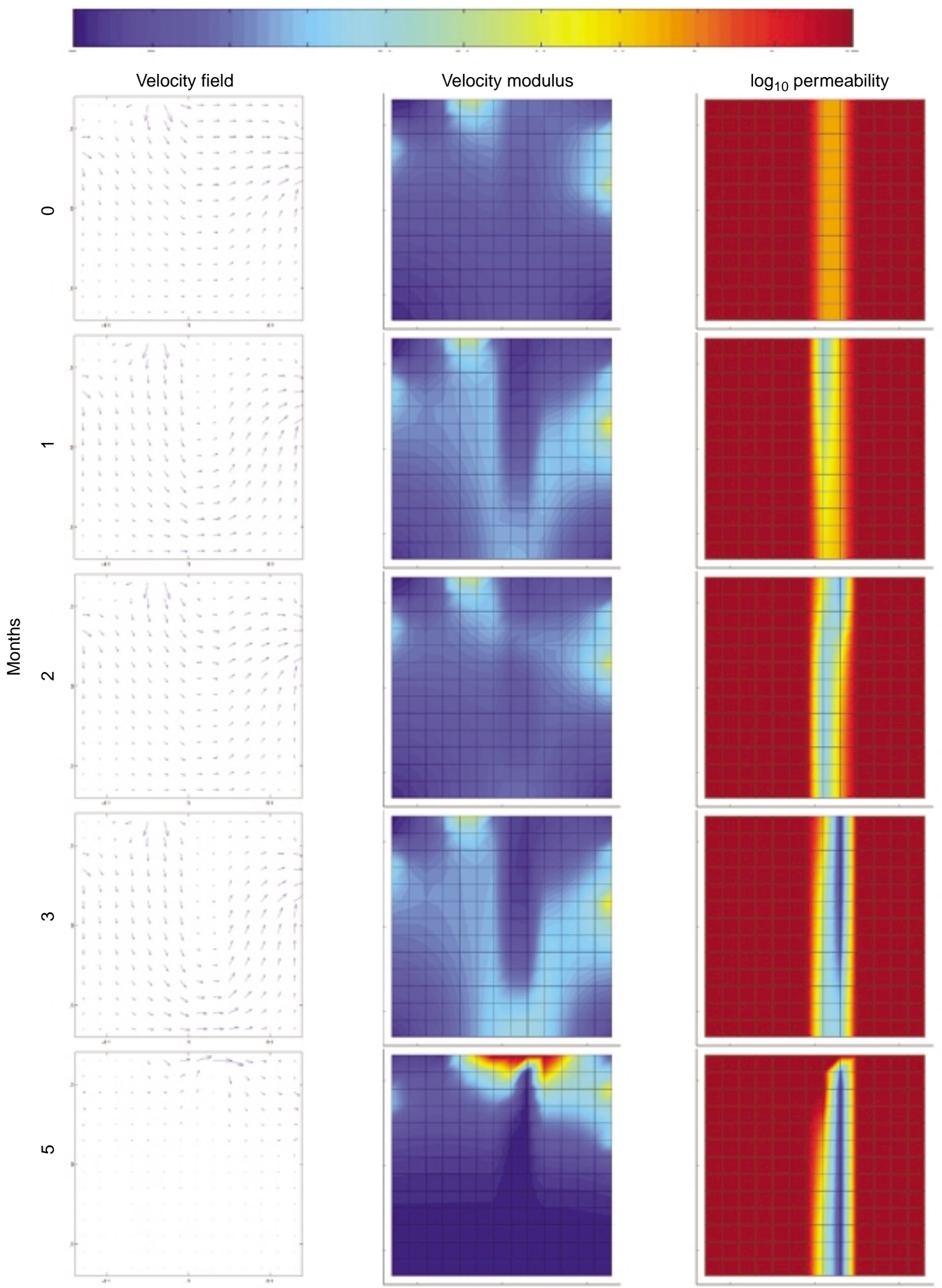

Figure 4

Evolution with time (between 0 and 5 months) of the velocity field and of the log of permeability. The scale (from blue to red) ranges from 0 to $610^{-7} \mathrm{~m} \mathrm{~s}^{-1}$ for velocity modulus and from -9 to -5 for $\log _{10}$ (permeability in $\mathrm{m} \mathrm{s}^{-1}$ ) (smoothed contours). 


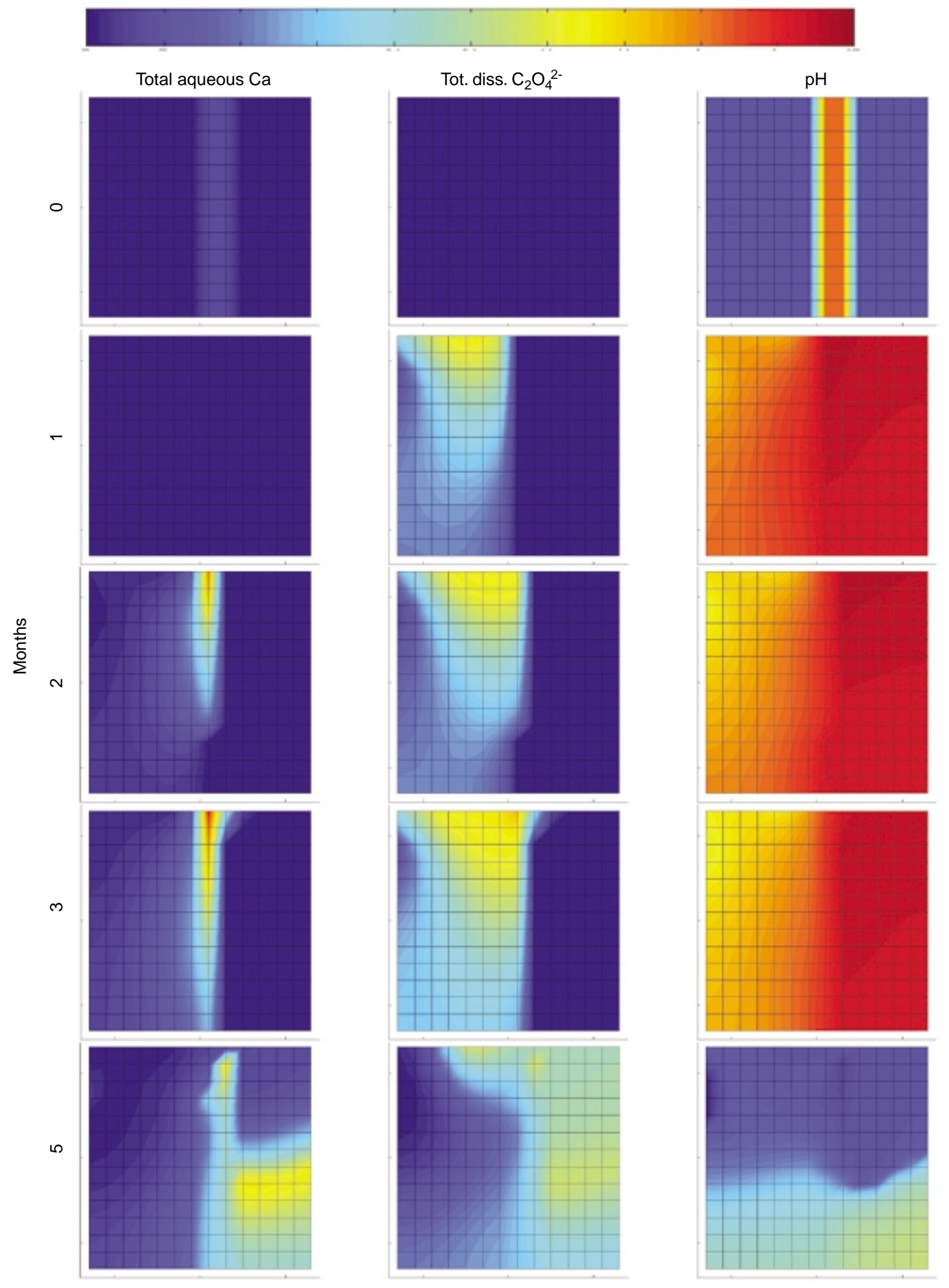

\section{Figure 5}

Evolution with time (between 0 and 5 months) of total aqueous $\mathrm{Ca}$, total aqueous $\mathrm{C}_{2} \mathrm{O}_{4}^{2-}$ and $\mathrm{pH}$. The scale (from blue to red) ranges from 0 to $0.12 \mathrm{~mol}^{-1}$ for $\mathrm{Ca}$, from 0 to $0.6 \mathrm{~mol}^{-1}$ for $\mathrm{C}_{2} \mathrm{O}_{4}^{2-}$ and from 6 to 14 for $\mathrm{pH}$ (smoothed contours). 


\section{FUTURE MILESTONES TOWARDS AN ACTUAL EXPERIMENT}

Before the numerical experiment presented here becomes an actual 2-D experimental benchmark, several difficulties will have to be overcome.

In a first stage, further numerical simulations are needed. The dynamics of this system appear to be complex. Spatial discretization refinement has been shown to modify the duration and period of the oscillations in the velocity field, hence further investigations on the impact of discretization options are necessary. The planned work on numerical simulation also includes comparisons with other codes using different numerical methods or discretization schemes (e.g. the Alliances simulation platform (Bengaouer et al., 2003; Mügler et al., 2004) and Crunch (C. Steefel, Lawrence Berkeley Laboratory). In particular, a comparison between codes built with global implicit algorithms and codes using operator splitting methods will certainly be fruitful. Computer time needed for these calculations is also to be explored. Preliminary predictions obtained with Crunch, a reactive-transport code using a global implicit algorithm that couples reaction and transport at every time step, confirm the sensitivity and the high non linearity of the studied system (C. Steefel, personal communication). Other simulations are also presently conducted by comparing the results obtained from iterative versus non iterative algorithms. When comparing codes, special care must also be given to relationships (like Eqs. (4) and (5) for permeability and diffusion coefficient) that are often similar but not strictly equivalent in different tools; small differences in such nonlinear relations may induce important changes in results. The same consideration applies to kinetic rate laws.

In a second stage, finalizing the actual design of the experiment will require some more bibliographical and experimental work, namely:

- the acquisition of reliable data on the precipitation kinetics of calcium oxalate and quartz sand reactivity at $\mathrm{pH} \sim 12$ on batch and column experiments;

- the elaboration of appropriate tracing techniques that will enable the monitoring of the clogging and dissolution/ precipitation processes during the experiment. Incorporation of radioactive trace elements in calcium oxalate could, for example, allow for a mapping of precipitates. Specific sensors (e.g. $\gamma$ camera, etc.) would then be necessary to obtain live images during the runs.

The building and testing of a 2-D experimental box will finally be possible when technical problems related to the elaboration of the composite reactive medium and to the solution inlets and outlets are solved. Simplifications and improvements of the present design, for example by suppressing inlet 1 , are still possible. The utilisation of a noncohesive material (sand) to fill the reaction chamber seems to be the simplest option to prepare the heterogeneous porous medium, as was done in previous 1-D experiments (Lagneau, 2000). This option presents however risks, e.g. easy formation of preferential channels by differential compaction due to pressure increase in regions of the reaction chamber or potential displacement of individual grains blocking selected flow paths by filtration. It will also raise difficulties when the solid properties are investigated at the end of the experiment (sampling and preparation of thin sections). Another critical practical point concerns the control of carbon dioxide: ingress of minute amounts of dissolved $\mathrm{CO}_{2}$ in the reaction chamber could provoke precipitation of calcite in the portlandite zone together with $\mathrm{Ca}$-oxalate and modify significantly the course of events during the experiment.

\section{CONCLUSION}

The design of a 2-D cementation experiment was elaborated using the reactive transport code Hytec in order to explore the couplings between flow, advection and chemical transformations in a porous medium. The numerical simulations showed that the best configuration for such an experiment uses a combination of a reactive porous medium and the injection of solutes at constant flow rate. The selected design involves the precipitation of a calcium oxalate wall in a flat square experimental reaction chamber $(280 \mathrm{~mm}$ side $)$. The growth of this wall of precipitated calcium oxalate formed as a result of the dissolution of portlandite, induces a strong porosity reduction and a marked deviation of the flow lines, which in turn modifies the oxalate precipitation process. Eventually, when portlandite is exhausted, the oxalate wall is perforated locally which induces another strong evolution of flux lines.

Further stages of the elaboration of the experiment include simulation benchmarks with other codes, acquisition of precise kinetic data on calcium oxalate precipitation and the selection of adapted tracing techniques to monitor the experiment non destructively and redundantly.

\section{ACKNOWLEDGEMENTS}

This study was supported by the CEA/Nuclear Energy Division, Direction de la Simulation et des Outils Expérimentaux. C. Steefel, D. Garcia and E. Brosse are gratefully acknowledged for their careful review and thoughtful comments on the manuscript.

\section{REFERENCES}

Archie, G.E. (1942) The Electrical Resistivity Log as an Aid to Determining some Reservoir Characteristics. Transactions of the American Institute of Mining Engineers, 146, 54-61.

Bengaouer, A., Montarnal, P., Loth, L. and Gaombalet, J. (2003) ALLIANCES Project: Integration, Analysis and Design Software 
Environment for Nuclear Waste Storage and Disposal. Int. Conf. on Supercomputing in Nuclear Applications, 22-24 Sept. 2003, Paris, France.

Carman, P.C. (1937) Fluid Flow through Granular Beds. Trans. Inst. Chem. Eng., 15, 150-166.

Chilingar, G.V., Main, R. and Sinnokrot, A. (1963) Relationship between Porosity, Permeability and Surface Area of Sediments. J. Sediment. Petrol., 33, 759-765.

Chilingarian, G.V., Torabzadeh, J., Riecke, H.H., Metghalchi, M. and Mazzullo, S.J. (1992) Interrelationships among Surface Area, Permeability, Porosity, Pore Size and Residual Water Saturation. Developments in Petroleum Science, 30, 379-397.

Cross, J.E. and Ewart, F.T. (1991) HATCHES - A Thermodynamic Database and Management System. Radiochimica Acta, 52/53, 421-422.

de Marsily, G. (1986) Quantitative Hydrogeology, Academic Press, London.

Giambalvo, E.R., Steefel, C.I., Fisher, A.T., Rosenberg, N.D. and Wheat, C.G. (2002) Effect of Fluid-Sediment Reaction on Hydrothermal Fluxes of Major Elements, Eastern Flank of the Juan de Fuca Ridge. Geochim. Cosmochim. Acta, 66, 10, 17391757.

Johnson, J.W., Nitao, J.J., Steefel, C. and Knaus, K.G. (2001) Reactive Transport Modeling of Geologic $\mathrm{CO}_{2}$ Sequestration in Saline Aquifers; The Influence of Intra-Aquifer Shales and the Relative Effectiveness of Structural, Solubility, and Mineral Trapping During Prograde and Retrograde Sequestration. First Annual Conference on Carbon Equestration, May 14-17th, 2001, http://www.netl.doe.gov/publications/proceedings/01/carbon_seq/ P28.pdf.

Lagneau, V. (2000) Influence des processus géochimiques sur le transport en milieu poreux; application au colmatage de barrières de confinement potentielles dans un stockage en formation géologique. Ph.D. Dissertation, École des mines de Paris, Fontainebleau, France.

Lagneau, V., Pipart, A. and Catalette, H. (2004a) Reactive Transport Modeling and Long Term Behavior of a $\mathrm{CO}_{2}$ Sequestration in Saline Aquifers. Oil and Gas Sci. Technol., this issue.

Lagneau, V., Trotignon L., Van der Lee, J. and Soreau, P. (2004b) Clogging of Porous Media due to Geochemical Reactions: Column Experiments and Numerical Simulations. Submitted to Water Resour. Res.

Le Gallo, Y., Bildstein, O. and Brosse, E. (1998), Modeling Diagenetic Changes in Reservoir Permeability, Porosity, and Mineral Compositions with Water Flow. In: Reactive Transport Modeling of Natural Systems, Steefel, C.I. and Van Cappellen, P. (eds.), J. Hydrology, 209, 366-387.

Lichtner, P.C. (1996) Continuum Formulation of MultiComponentMultiphase Reactive Transport. In: Reactive Transport in Porous Media, Reviews in Mineralogy, 34, 1-81, Mineralogical Society of America.

Lide, D.R. Editor (1994) Handbook of Chemistry and Physics, 75th Edition, CRC Press, USA.

Morel, F.M.M. (1983) Principles of Aquatic Chemistry, WileyInterscience, New York, USA.
Mügler, C., Montarnal, P., Dimier, A. and Trotignon, L. (2004) Reactive Transport Modelling in the Context of a Software Platform. Int. Conf. on Computational Methods in Water Resources, 13-17 June 2004, Chapel Hill, USA.

Sallès, J., Thovert, J.F. and Adler, P.M. (1993a) Deposition in Porous Media and Clogging. Chemical Engineering science, 48, 16, 2839-2858.

Sallès, J., Thovert, J.F., Delannay, R., Prevors, L., Auriault, J.L. and Adler, P.M. (1993b) Taylor Dispersion in Porous Media: Determination of the Dispersion Tensor. Physics of Fluids A., 5, 2348-2376.

Savage, D., Noy, D. and Mihara, M. (2002) Modelling the Interaction of Bentonite with Hyperalkaline Fluids. Appl. Geochem., 17, 207-223.

Soler, J.M. (2003) Reactive Transport Modeling of the Interaction between a High-pH Plume and a Fractured Marl: the Case of Wellenberg. Appl. Geochem., 18, 1555-1571.

Steefel, C.I. and Lichtner, P.C. (1998a) Multicomponent Reactive Transport in Discrete Fractures: I. Controls on Reaction Front Geometry. J. Hydrol., 209, 186-199.

Steefel, C.I. and Lichtner, P.C. (1998b) Multicomponent Reactive Transport in Discrete Fractures: II.: Infiltration of Hyperalkaline Groundwater at Maqarin, Jordan, a Natural Analogue Site. J. Hydrol., 209, 200-224.

Steefel, C.I. and MacQuarrie, K.T. (1996) Appraoches to Modeling Reactive Transport in Porous Media. In: Reactive Transport in Porous Media, Reviews in Mineralogy, Lichtner, P.C., Steefel, C.I. and Oelkers, E.H. (eds.), Mineral. Soc. Am., 34, 83-129.

Steefel, C.I., Carroll, S., Zhao, P. and Roberts, S. (2003) Cesium Migration in Hanford Sediment: a Multisite Cation Exchange Model Based on Laboratory Transport Experiments. J. Cont Hydr., 67, 219-246.

Trotignon, L., Fauré, M.H., Cranga, M. and Peycelon, H. (1998) Numerical Simulation of the Interaction between Granitic Groundwater, Engineered Clay Barrier and Iron Canister. In: Scientific Basis for Nuclear Waste Management XXII (Mater. Res. Soc. Proc. 556, Boston, 1998), 599-606.

Van der Lee, J. (1997) Modélisation du comportement géochimique et du transport des radionucléides en présence de colloïdes PhD. Dissertation, École des mines de Paris, Fontainebleau, France.

Van der Lee, J. (1998) Thermodynamic and Mathematical Concepts of CHESS. Technical Report LHM/RD/98/39, CIG, École des mines de Paris, Fontainebleau, France.

Van der Lee, J., de Windt, L., Lagneau, V. and Goblet, P. (2002) Presentation and Application of the Reactive Transport Code HYTEC. Comput. Meth. Water Resour., 1, 599-606.

Van der Lee, J., de Windt, L., Lagneau, V. and Goblet, P. (2003) Module-Oriented Modeling of Reactive Transport with HYTEC. Computers \& Geosciences, 29, 265-275.

Yeh, G. and Tripathi, V. (1991) A Model for Simulating Transport of Reactive Multispecies Components: Model Development and Demonstration. Water. Resour. Res., 27, 12, 3075-3094.

Final manuscript received in November 2004 or distributed for profit or commercial advantage and that copies bear this notice and the full citation on the first page. Copyrights for components of this work owned by others than IFP must be honored. Abstracting with credit is permitted. To copy otherwise, to republish, to post on servers, or to redistribute to lists, requires prior specific permission and/or a fee: Request permission from Documentation, Institut français du pétrole, fax. +33147527078 , or revueogst@ifp.fr. 